\title{
Méthod champenoise sparkling pear wine costs most, but offers highest quality
}

\author{
Glenn T. McGourty $\square \quad$ Christian E. Butzke
}

\begin{abstract}
Commercial production of pear cider could greatly improve the demand for pears that are not packed for fresh market or canned. Bringing pear cider, also called perry, to the marketplace will involve careful planning and market knowledge. The cost of producing pear still wine by custom crush is $\$ 275$ per ton of pears. The cost of finishing the cider varies with the approach. The classic sparkling wine méthod champenoise, involving a secondary fermentation in the bottle, was the most expensive, but yielded the highest-quality beverage. Bottling and packaging the value-added product also varied in price. The retail costs would be $\$ 3$ for a 22-ounce bottle of pear cider and \$6 for a 750-milliliter bottle of sparkling pear wine.
\end{abstract}

In the first part of our study, we explored a new market channel for California pear growers and packers (see page 31). We investigated the different production options for making premium quality pear cider (perry). The classic sparkling wine méthod champenoise, involving a secondary fermentation in the bottle, yielded the highest-quality beverage. Méthod champenoise is the same fermentation process used to produce French champagne. We concluded that existing sparkling winemaking technology is appropriate and available for the immediate implementation of our pilot project.

In the second part of our study, we address regulatory issues and provide a cost analysis for the commercial production of this value-added product, which could greatly improve the de- mand for pears that are not packed for fresh market or canned.

\section{Custom cider-making costs}

The following cost data were supplied by a custom wine-making facility located in Mendocino and Sonoma counties that is a full-service beverage producer.

The following assumptions are made: A truckload of pears ( 24 tons) is sourced from a Mendocino County packing house presorted, being mostly small, sound fruit free of rot, overripeness or any other microbiological defects. An allowance is made for cooling and storage, because not all fruit will be processed at once. The pears are trucked to a custom crush facility where they are processed into juice, yielding on the average 160 gallons per ton, or 3,840 gallons of juice per load. The juice is then delivered to the custom crush winery. At this point, fermentation is performed to make the juice into a still wine. Included in the cost of fermentation are juice receiving, cold fermentation, clarification, heat and cold stabilization, and acid adjustments. Table 1 shows typical charges for a 24-ton load.

At this point, several different approaches could be used to finish the cider. The still wine could be bottled with pressurized $\mathrm{CO}_{2}$, labeled and then finished. For the same cost, the still wine could be mixed with additional sugar and yeast and then bottled. Fermentation would then finish in the bottle (known as "bottle conditioned" in the brewing trade). The costs for either system would be about the same. Two different sizes of containers are quoted; a case of twentyfour 12-ounce bottles and a case of twelve 22-ounce bottles. Kegging can also be done. For our purposes, kegs are priced at $\$ 90$ for a 15 -gallon size, and are assumed to be useable for 36 fillings. For the champagne method, we estimated the expenses for a case of twelve 750-milliliter bottles (table 2). Bottling in 750-milliliter bottles costs more due to a more expensive bottling system and more expensive materials needed.

Discussions with Peter Chia, a buyer for Beverages \& More, Inc., indicate that markup and profit margins of cider would most likely follow those of beer. Typically, wholesalers have a margin of about $18 \%$ over the producers' prices, with retailers' margins adding an additional $25 \%$ (table 3 ).

\section{Marketing considerations}

Bringing pear cider to the marketplace will involve careful planning and market knowledge. Ciders are not well known as a product, although they are growing well as a segment of the beverage industry. Positioning the product in the marketplace will require careful consideration of the consumer, as well as the product attributes that will make it desirable for consumption. This section was developed following discussions with selected beverage professionals involved in wholesale and retail marketing of wine, beer and spirits. Following the concept of the "Four P's of Marketing" (product, place, promotion and price), here are some ideas to be incorporated in developing a marketing strategy for pear cider.

Product. Pear cider is a light, dry, refreshing product that has half the alcohol (and therefore half the calories) of wine. It is fragrant of pears, tart, crisp and bubbly, with a creamy mouth feel followed by a lingering fruit taste finish with a slight bitterness and tannic structure. It is rela- 
tively inexpensive to produce compared to wine, due to the low cost of fruit and the short time required to finish fermentation. It is a regional product from California's wine country (Lake and Mendocino counties, the Sacramento Delta and, when blended with apples, Sonoma County). There is plenty of fruit available at a reasonable cost to ensure growth of this beverage in the market place. There is the possibility of making interesting blends using 'Bartlett' pears with winter pears ('Comice', 'Winter Nelis', 'Bosc') and older apple cultivars ('Sierra Beauty',
'Winesap', 'Rhode Island Greening', 'New town Pippin'). In this way, a diverse product line could be offered that is strongly regional in nature, paralleling the wine industry.

Bureau of Alcohol, Tobacco and Firearms regulations are much more lenient with ciders (which they classify as "fruit wines") than with wine regarding blending with flavorings, water and sugar. The development of flavored ciders with other fruit juices, spices and herbs allows for a great variety of potential product. Cider tastes good with a wide array of foods, from

\section{BATF tax regulations for cider}

1. Production of cider or perry requires bonding similar to wineries.

2. The Taxpayer Relief Act of 1997 added a new tax class for wine, called hard cider, to section 5041 of the Internal Revenue Code (26 U.S.C. 5041), with a tax rate of 22.6 cents per gallon. This new tax class does not apply to products other than apple cider: Hard cider is derived primarily from apples or apple concentrate and water, containing no other fruit product (therefore excluding perry), and containing at least $0.5 \%$ and not more than $7 \%$ of alcohol by volume. Wineries eligible for the small winery tax credit are also eligible for a credit of 5.6 cents per gallon of cider, making the net tax rate on cider 17 cents per gallon. Production and removal of the cider is counted along with wine for determining eligibility for the small winery tax credit, and must be shown on the Report of Wine Cellar Operations. The effective date of this statutory change was Oct. 1, 1997. For more information or copies of the implementing regulations, contact ATF Regulations Division Coordinator Marjorie Ruhf at (202) 927-8202; or see http://www.wineinstitute.org/ newstuff/winelaw/taxpayer_relief_act_ sections_908.htm.

The federal tax rates for all alcoholic beverages are listed at http://www. atf.treas.gov/core/alcohol/info/ atftaxes.htm.

3. Because BATF views perries as fruit wines, they are taxed at the rate of $\$ 1.07$ per gallon when over 150,000 gallons per year are produced. Under that amount, these wines are taxed at the hard cider rate of 17 cents per gallon. In order to be considered still wines, they must have less than $0.39 \mathrm{~g} \mathrm{CO} 2 / 100 \mathrm{~mL}$ of wine. This is about the same as 0.2 $\mathrm{MPa}$ of pressure in the bottle. If the amount of $\mathrm{CO} 2$ exceeds $0.39 \mathrm{~g} / 100 \mathrm{~mL}$ of wine, it is considered a sparkling wine, and the tax rate jumps to a prohibitive $\$ 3.40$ per gallon.

4. In California, the state excise tax for cider and perry is the same as for both beer and wine, 20 cents per gallon. In Washington state, hard cider (including perry) has been placed in a lower excise tax category than wine (http:// www.taxadmin.org/fta/rate/ wine.html), similar to the rate charged for beer (http://www.taxadmin.org/fta/ rate/beer.html) at 30.8 cents per gallon. To be classified as hard cider, the alcohol volume must be not less than $0.5 \%$ and not more than $7.0 \%$.

5. Additional flavorings, sugar and water are legal to add to fruit wines. Consult BATF wine technical advisor Richard Gahagan (telephone (209) 487 5093) for permissible amounts as well as labeling and packaging guidelines. According to statute 26 U.S.C. 5662 , purveyors need to be careful that the packaging does not represent the pear product to be a sparkling wine unless it is tax paid as sparkling wine.

In the past 2 years, several wineries have also teamed up with microbreweries to share their resources and expand their clientele (http:/ / smartwine.com/wbm/ 1996/bm019605.htm). strong cheeses and hearty stews to spicy foods, such as Mexican, Thai and Chinese cuisines. The tartness and bubbly mouth feel allow this beverage to pair well with strongflavored foods.

Place. Pear ciders can be easily distributed throughout the traditional three-tier marketing system used by the alcoholic beverage industry. They can find a variety of market niches, ranging from a small farmstead cidery (an on-farm enterprise) producing several thousand cases a year to a large winery producing millions of cases.

A potential niche for ciders is the microbrewery or "brew pub," small breweries that make beer on premise. In Ireland and Britain, cider is offered on tap and by the bottle at local pubs. Ciders offer a logical alternative to beer for the customer who goes to a brew pub, but doesn't like the filling and bitter flavors of a high-quality craft brew. People who go to brew pubs appreciate high-quality beverages presented in a comfortable ambiance, and they are willing to pay for that product and service. The cider industry would find a natural alliance with the brewing industry, and could probably use similar marketing channels for distribution. The North Coast of California also prides itself on its regional cuisine, so many establishments would be receptive to an interesting and flavorful local beverage. In Northern France, in the province of Britanny, cider is the traditional beverage to accompany the regional cuisine, especially crêpes. In fact, several crêperies in San Francisco offer imported cider by the pitcher. Finally, attractively bottled ciders would fit well into North Coast delicatessens and grocery stores catering to the tourist picnic trade, especially if they are promoted as a regional beverage.

Promotion. For a small cider business, building on the theme of regionality would be an important component of a marketing program. Tourism, hospitality and restaurant businesses are logical targets for this class of beverages, because there are motivated customers who want to experience regional cuisine and are willing to try new foods and beverages. For a larger-scale business, ciders com- 
pete with wine coolers, beer and other beverage choices. Producers would want to focus on its fresh fruit base, lower caloric content (compared with wine), refreshing taste and compatibility with a wide range of foods. It would still make sense to make a regional beverage to distinguish California Pear Cider from New England and European ciders:

Price. Finding the proper price points for a high-quality, hand-crafted cider will be somewhat challenging. Cider as a product is more closely aligned with beer than with wine, which implies lower prices and smaller margins, but more volume and quicker turnover than wines. Ciders presently available in the market place are priced relatively cheaply because in most cases they are a fairly "industrial" product made from concentrates instead of fresh juice, artificially carbonated, and minimally aged or otherwise carefully crafted. A high-quality cider with natural carbonation produced either as a bottle conditioned product, by bulk charmat or by kegging should retail in the same price range as a high-quality, craft brew beer. There may be a limited opportunity for a premium product produced similar to sparkling wine, but less expensive in price.

Retailers report that most of the activity in the present marketplace is for ciders that sell in the price range of $\$ 2.00$ to $\$ 3.50$ per 32-ounce bottle. Some of the imported ciders are selling well in the range of $\$ 4.00$ to $\$ 5.00$ per 32-ounce bottle. Clearly, the more hand-crafted products would fit in the latter range, and a premium product could probably be sold in the range of $\$ 6.00$ to $\$ 7.00$ a bottle. This kind of product would have to be a blend of interesting-tasting varietals, bottle fermented, perhaps with the initial still wines barrel aged in the traditional approach of cider making. On tap in the brew pub or in the restaurant, ciders would probably retail in the same price range as beer.

\section{Perry economically feasible}

Making a sparkling pear cider from juice grade Bartlett pears is feasible from both economic and enological perspectives. The resulting beverage is

TABLE 1. Costs to produce pear still wine, custom crush

\begin{tabular}{|c|c|c|}
\hline & Cost per ton & Cost per gallon of juice \\
\hline & \multicolumn{2}{|c|}{ 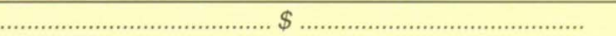 } \\
\hline Purchase fruit & 50.00 & 0.31 \\
\hline Cooling and storage & 11.00 & 0.07 \\
\hline Transportation for juicing & 12.00 & 0.07 \\
\hline Crushing and filtering & 72.00 & 0.45 \\
\hline Transport juice to winery & 5.00 & 0.03 \\
\hline Custom fermentation & 125.00 & $\underline{0.77}$ \\
\hline Total to still wine & 275.00 & $\overline{1.70}$ \\
\hline
\end{tabular}

TABLE 2. Estimated bottling and packaging costs using Charmat, Traditional and Champagne methods

\begin{tabular}{|c|c|c|c|c|}
\hline & \multicolumn{4}{|c|}{ Cost } \\
\hline & 12 22-oz bottles & 24 12-oz bottles & 15-gal keg & $12750-\mathrm{mL}$ bottles \\
\hline & \multicolumn{4}{|c|}{. } \\
\hline Wine & 3.60 & 3.82 & 25.50 & 4.37 \\
\hline Bottling & 1.80 & 1.90 & 12.75 & 12.00 \\
\hline Packaging & $\underline{5.00}$ & $\underline{6.00}$ & $\underline{2.50} /$ fill* $^{*}$ & $\underline{8.00}$ \\
\hline Total & 10.40 & 11.72 & 40.50 & 24.37 \\
\hline
\end{tabular}

${ }^{\star}$ Assumes that a keg is good for 36 fills, with initial cost of $\$ 90=\$ 2.50$ per fill.

TABLE 3. Comparison of probable prices and margins for ciders in different packaging and styles

\begin{tabular}{|c|c|c|c|c|}
\hline & \multicolumn{4}{|c|}{ Cost } \\
\hline & 12 22-oz bottles & 24 12-oz bottles & $12750-\mathrm{mL}$ bottles & 15-gal keg \\
\hline & & & . & ............... \\
\hline Production & 10.40 & 11.72 & 24.37 & 40.50 \\
\hline FOB cidery & 22.15 & 17.25 & 44.25 & 82.00 \\
\hline Distributor markup & 27.00 & 21.00 & 54.00 & 100.00 \\
\hline Retail markup & 36.00 & 28.00 & 72.00 & $320.00^{*}$ \\
\hline Retail price per unit & 3.00 & 1.17 & 6.00 & $2.00^{*}$ \\
\hline
\end{tabular}

*Sold on tap in 12-oz. servings in a restaurant or bar

light, refreshing, distinctive and good tasting. There is an adequate supply of juice-grade pears to allow an industry to grow to a healthy size with existing stocks of fruit. If blended with juicegrade apples, the pool of available fruit would double. Having a cider market option. would greatly benefit the North Coast pear and apple industries, and over time would make profitable markets for fruit produced with relaxed cosmetic standards. The mix of older processing apple cultivars along with an ample supply of Bartlett pears would permit the creation of a regionalized beverage that could not be easily created in other locations.

The best cider is produced from fresh juice rather than from concentrate. The juice should be fermented using standard wine-making practices commonly used by most California wineries, including excellent sanitation, acidification of the juice, selected strains of yeast, judicial use of sulfur dioxide and controlled fermentation temperatures to retain as much fruit aroma and flavor as possible. Natural carbonation is strongly preferred to artificial carbonation. The bottle fermen- tation méthod champenoise, adopted from ultrapremium sparkling wine production, in combination with a brief bottle aging, yields outstanding results. Although this research project demonstrated the feasibility of using Bartlett pears for cider, more refinement on production is needed, including studies on fermentation temperatures, yeast strains, product stability, optimum sugar and acidity levels, and additional blends and flavorings.

The marketing channels for cider will probably closely parallel those of craft brew beers; they are presently sold at about the same price points. Anyone contemplating entering the market should consider working with a beer distributor who expresses interest in developing a cider product line. Presently there are not many cider brands available, and product is limited in supply. Given the strong growth of the cider market in the last 10 years, there appear to be opportunities for this beverage to grow in volume.

Growing a brand from a small regionally produced product to a larger more widely distributed product 


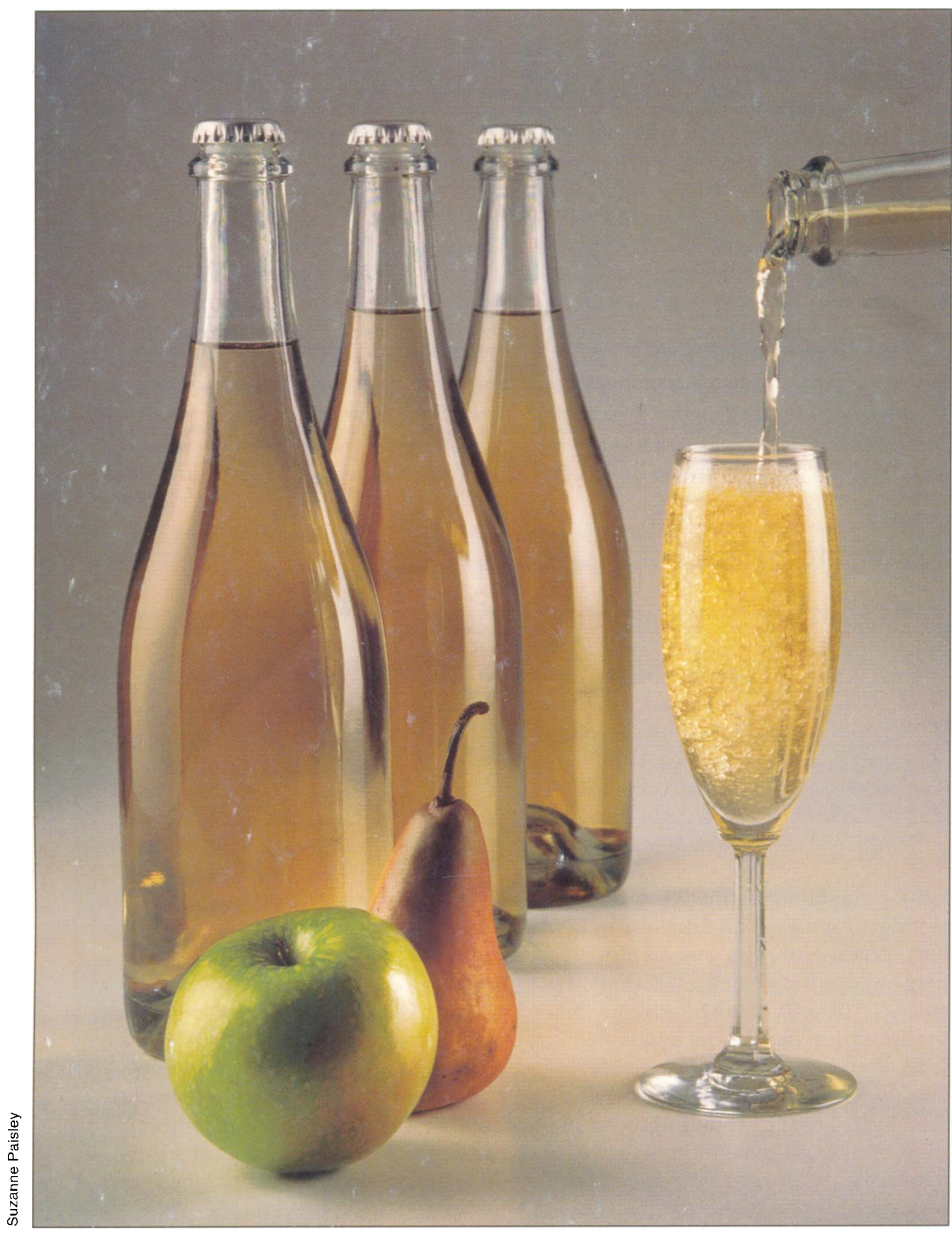

The cost of producing pear cider varies with the approach. The classic sparkling wine method champenoise, involving a secondary fermentation in the bottle, is the most expensive, but yields the highest-quality beverage. would make sense. There are custom crush wineries that can produce the entire product from start to finish. For small brands, this would allow the organization to focus on marketing, a key need for the development of cider as a segment of the beverage industry. At the same time, their product is produced with state-of-the-art equipment by experienced and knowledgeable people. Small brands will need good margins generated from selling a highquality, regional product at a premium price. Producing and selling kegged cider would make sense as well, distributing to bars and restaurants that feature craft brews and other highquality beverages on tap.

Larger brands will be profitable if they are able to generate a greater volume of high-quality product with a quick turnover, taking advantages of economies of scale that work well when considerable product is being manufactured. Even on a custom crush basis, there is capacity in the North Coast for a 500,000-case operation in place at this time. Timely movement into this still young industry could allow a moderate-sized operation to create a strong market position. However, there would need to be considerable investment in marketing and promotion to make this happen.

G.T. McGourty is Viticulture and Plant Science Advisor, UC Cooperative Extension, Mendocino and Lake counties; and C.E. Butzke is UCCE Enology Specialist and AES Enologist in the Department of Viticulture and Enology, UC Davis.

This research project was funded by the California Pear Advisory Board.

\section{CALIFORNIA AGRICULTURE ASSOCIATE EDITORS}

Animal, Avian, Aquaculture
\& Veterinary Sciences
Christopher M. Dewees
Kathryn Radke
Barbara A. Reed

Barbara A. Reed

Economics \& Public Policy

George E. Goldman

Richard A. Howitt

Alvin Sokolow

Food \& Nutrition

Eunice Williamson

\section{Human \& Community Development \\ Linda M. Manton Karen P. Varcoe}

Land, Air \& Water Sciences

John Letey

Natural Resources

Daniel W. Anderson

Lynn Huntsinger

Richard B. Standiford
Henry J. Vaux, Jr. http://danr.ucop.edu/calag/

CALAG@ucop.edu

PH: $510987-0044$

FAX: $510465-2659$
Joseph G. Hancock

Michael K. Rust

Robert K. Washino

Plant Sciences

Jodie S. Holt

Lee F. Jackson

G. Steven Sibbett 